\title{
Mechanical and Microstructural Properties of Redispersible Polymer-Gypsum Composites
}

\author{
Carlos Eduardo Marmorato Gomes ${ }^{a}{ }^{\circledR}$, Adla Kellen Dionísio Sousa ${ }^{b}$, Maria Emília da Silva Oliveira
}

\author{
Araujo $^{c}$, Sara Beloti Ferreira ${ }^{d}$, Patricia Fontanini ${ }^{e}$ \\ ${ }^{a}$ Faculdade de Engenharia Civil, Arquitetura e Urbanismo, Universidade de Campinas, \\ Campinas, SP, Brasil \\ ${ }^{b}$ Universidade Federal Rural do Semiárido, Mossoró, RN, Brasil \\ ${ }^{c}$ Universidade Presbiteriana Mackenzie, Campinas, SP, Brasil \\ ${ }^{d}$ Instituto Federal do Sul de Minas Gerais, Poços de Caldas, MG, Brasil \\ ${ }^{e}$ Universidade Estadual de Campinas, Campinas, SP, Brasil
}

Received: February 16, 2018; Revised: January 09, 2019; Accepted: March 28, 2019

\begin{abstract}
Studies on gypsum modified by polymers have been conducted to assess the potential of improvement in the mechanical performance, water resistance and increasing the setting time, facilitating its handling. Gypsum-based compounds made with different additions of redispersible polymers were studied, such as: ethylene-vinyl acetate (EVA), vinyl acetate terpolymer, vinyl laurate and vinyl chloride (VA/VL/VC), and vinyl acetate and vinyl versatate (VA/VeoVA). The influence on setting time, microstructural formation and on the bending performance was assessed, as well as and compression of the hardened gypsum. The composites were prepared using a polymer concentration of $5 \%$ and $10 \%$, and water/gypsum ratio of 0.6 . The addition of the polymer decreased the structural robustness and change in the microstructure. We concluded that the reduction in the amount of water through additives may allow a more complete and robust training of gypsum crystals and compounds with better mechanical performance.
\end{abstract}

Keywords: Polymer-modified gypsum, Redispersible polymer, Mechanical properties, Microstructural properties.

\section{Introduction}

Gypsum has low plastic resistance and may suffer fractures when subjected to the tractive effort because of its covalent and ionic bonds, which give greater force and proximity to the molecules. Many studies ${ }^{1-5}$ have been made using gypsum-based composite materials (GBCM) with polymers with the goal of enhancing its performance. The polymeric materials have extensive chains composed of repetitions of units that are joined by weak Van der Waals bonds ${ }^{6,7}$, giving greater flexibility than the ceramic materials.

The use of redispersible polymers to modify the properties of gypsum-based composites, whether fresh or hardened, has been increasing. Different from the polymers in emulsion, these polymers undergo a drying step and receive other components, such as bactericides and anti-foaming agents; it may also include clays, silica, and calcium carbonate, such as anti-agglomeration loading. Thus, when the dust comes in contact with the water, a dispersion and a re-emulsification occur, reaching the latex form with particles from 1 to $10 \mu \mathrm{m}^{8}$.

In the fresh state, the addition of polymers interferes mainly in the setting time, hydraulic retraction and plasticity of gypsum plaster. In the hardened state, the polymers can influence properties, such as tensile strength, flexural strength, adhesion to surfaces, permeability, abrasion resistance and

*e-mail: cemgomes@fec.unicamp.br chemical resistance. All these properties are related to the type of polymer employed.

The modification concept can be explained by the interaction of the polymer with the gypsum matrix. In this sense, there is the formation of an organic co-matrix that interpenetrates the mineral matrix during polymerization, filling the voids and pores of this composite.

The process of forming a gypsum matrix comprises the steps of dissolution, crystallization and stiffening. When the modification by polymers occurs, the stiffening mechanism occurs basically in the same way. Thus, after the mix of hemihydrate- $\beta\left(\mathrm{CaSO}_{4} \cdot 0.5 \mathrm{H}_{2} 0\right)$ with water, the setting process begins, forming calcium sulfate dihydrate $\left(\mathrm{CaSO}_{4} \cdot 2 \mathrm{H}_{2} 0\right)$ accompanied by the stiffening of the material. During setting, the hemihydrate dissolves in water and forms the ions $\mathrm{Ca}^{2+}$ and $\mathrm{SO}_{4}^{2-}$, producing calcium sulfate dihydrate, which precipitates under Chatellier's Principles. Thus, the mechanism continues until the entire semi-hydrated gypsum pass through the three stages and forms the crystals of $\mathrm{CaSO}_{4} \cdot 2 \mathrm{H}_{2} 0$.

In the modified composites, polymerization occurs simultaneously and when it ends, a polymer matrix is obtained in the form of net or film ${ }^{2}$. The polymer forms a sort of sticky gel that adds the gypsum crystals, forming thus a more consistent composite, as it eliminates the mechanical limitations of the gypsum because of the empty spaces between the crystals of $\mathrm{CaSO}_{4} \cdot 2 \mathrm{H}_{2} \mathrm{O}$ formed, which are filled by polymer tape 
that envelops the blocks of crystals. By this principle, the polymeric film formation and its coalescence influences the whole stiffening process of the matrix.

Gypsum plaster with high dosages of acrylic latex may present significant delay in hydration, but they show increased plasticity and potential to reduce the water/gypsum ratio ${ }^{1}$. Depending on the intended use, the delay in the setting time could prove advantageous, since it allows a larger interval to work with the dry gypsum, such as in applications of gypsum in finishing surfaces. Considerable part of gypsum waste occurs, in part, at the time of application, because if it is not applied on time, the hardening process begins, hindering its handling.

The use of insoluble or poorly soluble monomers such as methacrylate or polymers, such as metallic stearates, acrylics, methacrylates, is known to give hydrophobic property to the gypsum matrix. The efficiency of this hydrophobic process can be subjected to high concentrations or doses of these polymers $^{1,9,10}$.

The consistency index and the setting time of modified gypsum by polyvinyl alcohol (PVA) is also changed ${ }^{11}$. The PVA addition increases the initial and end of the setting time of the gypsum. In contrast, content above $0.80 \%$ improved the plasticity, which can be explained by the morphology of the PVA particles that act as a lubricant.

The effects of polyacrylic ester emulsion (PEE) revealed a delay of the hydration of gypsum for levels from $1 \%$ to $1.5 \%$ polymer $^{12}$. In this case, the incorporation of polyacrylic ester formed a film on the gypsum particles, which restricted and delayed its hydration. Concerning PEE, we observed increments of compression strength of the modified gypsum, possibly because of the filling of the matrix voids, which can change the morphology of the crystals from the calcium sulfate dihydrate phases, thus refining the pore structure ${ }^{3,11}$.

The bending strength and modulus of elasticity of gypsum with addition of styrene-butadiene rubber (SBR) for levels of $5 \%, 10 \%$ and $20 \%$ compared with the reference sample, increased the bending strength of the composite ${ }^{2}$. This increase can be attributed to the envelopment of gypsum crystals by polymer adhesive film through a microstructural entanglement, making the material less fragile and more deformable.

In this study, we analyzed the effects of three redispersible polymers on the microstructural formation and mechanical properties of gypsum.

\section{Experimental Procedure}

\subsection{Materials}

The following materials were employed:

a. $\beta$-calcium sulfate hemihydrate $\left(\beta-\mathrm{CaSO}_{4} \cdot 1 / 2 \mathrm{H}_{2} \mathrm{O}\right)$;

b. Copolymer powder and ethylene-vinyl acetate (EVA), apparent density of $490-590 \mathrm{~kg} / \mathrm{m}^{3}$, size of the redispersible predominant particle of $4 \%$ on $400 \mu \mathrm{m}$, minimum temperature of $4{ }^{\circ} \mathrm{C}$ of film formation;

c. Copolymer powder of vinyl acetate/vinyl versatate (VA/VeoVA), apparent density: $500 \mathrm{~kg} / \mathrm{m}^{3}$, predominant particle size: $80 \mu \mathrm{m}$, minimum temperature of $6^{\circ} \mathrm{C}$ of film formation;

d. Terpolymer powder of vinyl acetate, vinyl laurate and vinyl chloride (VA/VL/VC), apparent density: $400-500 \mathrm{~kg} / \mathrm{m}^{3}$, predominant particle size of $80 \mu \mathrm{m}$, minimum temperature of $4{ }^{\circ} \mathrm{C}$ of film formation;

e. Potable water.

\subsection{Sample preparation}

To study the influence of using redispersible polymers on mechanical and microstructural properties of the gypsum we adopted the content of $5 \%$ and $10 \%$ in gypsum putty (Table 1). The polymer was added in anhydrous gypsum and homogenized still dry, forming a powder mixture. Then the powder was mixed with the water in the mortar mixer. The mixing time was standardized in $1 \mathrm{~min}$ for all samples. The unmodified gypsum matrix was used as standard. The water/gypsum and water/(gypsum + polymer) ratio was kept constant at 0.60 in mass. Prepared samples were cast into 40x40x $160 \mathrm{~mm}$ prismatic molds and cured for 21 days in laboratory conditions at $25.2{ }^{\circ} \mathrm{C}$ and relative humidity of about $75 \%$.

\subsection{Setting time and Mechanical characterization}

Setting time of pastes was performed according to the ASTM C $472^{13}$. The mechanical characterization, flexural and compressive strength, was performed according to ASTM C348 ${ }^{14}$ and ASTM C349 ${ }^{15}$, respectively. Three samples were adopted for bending under three loading points and six samples were adopted for compression. Both portions of each broken prism in bending were used for testing compression strength.

\subsection{Observations by SEM}

The composites were observed in Scanning Electron Microscopy (SEM), obtained by a LEO 440 scanning electron microscope. In addition, Energy-Dispersive X-ray

Table 1. Composition of polymer in each sample.

\begin{tabular}{lc}
\hline Sample & Polymer content (\%) \\
\hline Reference & - \\
EVA & 5 \\
& 10 \\
VA/VL/VC & 5 \\
& 10 \\
VA/VeoVA & 5 \\
\end{tabular}


Spectroscopy (EDS/EDX) analyses were held to verify the influence of these polymers on the hydration of gypsum.

\section{Results and Discussion}

The samples with EVA and VA/VL/VC polymers resulted in longer initial and final setting times (Figure 1). However, the one for EVA addition had less expressive retard, the final setting times very close for $5 \%$ and $10 \%$ contents. Thus, we observed that the setting times were not directly proportional to the EVA contents employed. Gypsum pastes modified by $\mathrm{VA} / \mathrm{VL} / \mathrm{VC}$, on the other hand, had an enhanced increase in setting times for both addition contents. The $5 \%$ addition of VA/VL/VC caused the increase of the final setting time from $35.5 \mathrm{~min}$ to $82 \mathrm{~min}$, while with the $10 \%$ addition, the final setting time occurred in $106 \mathrm{~min}$. The setting time process of gypsum can be divided into three steps: dissolution of the hemihydrate, nucleation of the gypsum crystals and growth of the $\mathrm{CaSO}_{4} \cdot 2 \mathrm{H}_{2} \mathrm{O}$ crystals ${ }^{16}$. When mixed with water, the $\mathrm{CaSO}_{4} \cdot 0.5 \mathrm{H}_{2} \mathrm{O}$ is quickly dissociated, forming $\mathrm{Ca}^{2+}$ and $\mathrm{SO}_{4}^{2-}$ ions and, after saturation, it forms the dihydrate and precipitates ${ }^{17}$. Thus, the extensive increase in setting time for $\mathrm{VA} / \mathrm{VL} / \mathrm{VC}$ can be due to the change in the rate of growth of dihydrate crystals. The retard of the setting time is also due to the decrease of the heat release rate, right after the mixing time of gypsum with water. At the initial setting time, the heat release rate is reduced, this time is considered a dormant period in which the reactions are decelerated and allows the manipulation of pastes before the setting ${ }^{18}$. Therefore, the VA/VL/VC polymer can be a strong inhibitor of dihydrate formation, with consequent retard of crystal growth and gypsum setting time. The $5 \%$ addition of VA/VeoVA caused a change in the setting times with regard to the reference specimen. For the 5\%

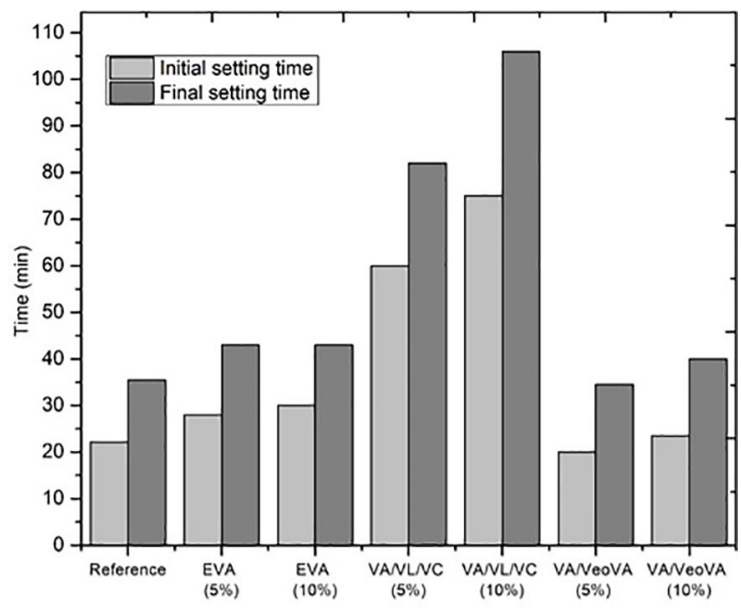

Figure 1. Initial and final setting time of modified gypsum. content, the polymer evidenced no retard of hydration and crystallization of gypsum; on the contrary, the use of VA/ VeoVA in gypsum may have increased the rate of nucleation of crystals, which, in turn, increased the crystallization, possibly acting as an accelerator of setting. Eve et al. ${ }^{19}$ also noted that the VA/VeoVA did not slow the setting time of gypsum mixtures when employing low contents, however the authors mention the increase of setting time for greater polymer concentrations. In this study, we observed that the $10 \%$ addition of VA/VeoVA caused slight increase in the setting time from $35.5 \mathrm{~min}$ to $40 \mathrm{~min}$. Thus, the increase in polymer concentration for values greater than $10 \%$ may cause greater retard in hydration, and consequently in the setting time.

Related to mechanical properties, the addition of polymers decreased the flexural strength of the composites (Figure 2). However, for the samples with 5\% EVA and VA/ VeoVA the decrease was approximately of $5 \%$, being much steeper for the sample with the VA/VL/VC terpolymer. Also, we observed that this decrease was greater as the levels of polymers increased.

With this technology, we expect to obtain a slight increase in flexural strength of modified gypsum composites, provided by the formation of polymer microfibers inside the matrix that can control cracks, especially their intensity, acting thus as a strengthening element, once it may cross over and sew such cracks.

In the scanning electron microscopy images, the formation of these fibrils can be seen in a much more intense and visible way for the VA/VL/VC terpolymer, not enough to increase the flexural strength of the gypsum. Although it was not the objective of this study, this can increase flexibility, i.e. reduce the modulus of elasticity of the gypsum matrix.

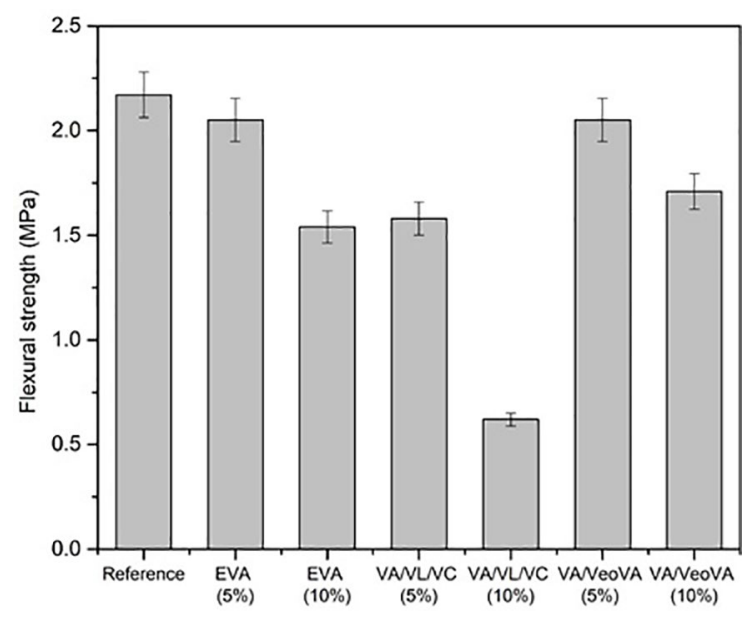

Figure 2. Flexural strength of modified gypsum. 
Clearly, the addition of polymers changed the compactness of the matrices (Figure 3). This fact is closely linked to the decreases observed in the structural robustness. The compactness of the reference sample is greater when compared with the modified matrices. Although the formation of the polymeric film was visible and easily identified, the incorporation of air was probably more intense in the modified matrices. The incorporation of air is a characteristic inherent in this technology, but its intensity depends on the polymer employed.

We could observe that a film surrounding the dihydrate crystals was formed after the addition of $10 \%$ polymers to the gypsum. However, such a film could not consistently envelop the crystals. This result differs from the studies by Rubio-Avalos et al. ${ }^{2}$, who found that the gypsum crystals are completely enveloped by a cohesive polymer film without leaving voids in the gypsum/polymer matrix.

The dihydrate crystals, formed after the mixture of gypsum with water, are the first ones to be formed and are the basis of where the next crystals will be formed. The first crystals are unstable and only minutes later they become stable and start to bond, forming large clusters in a needle

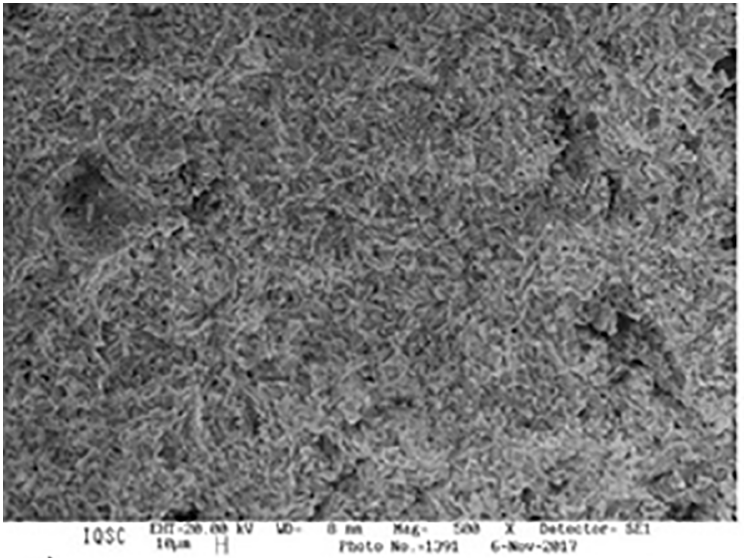

a)

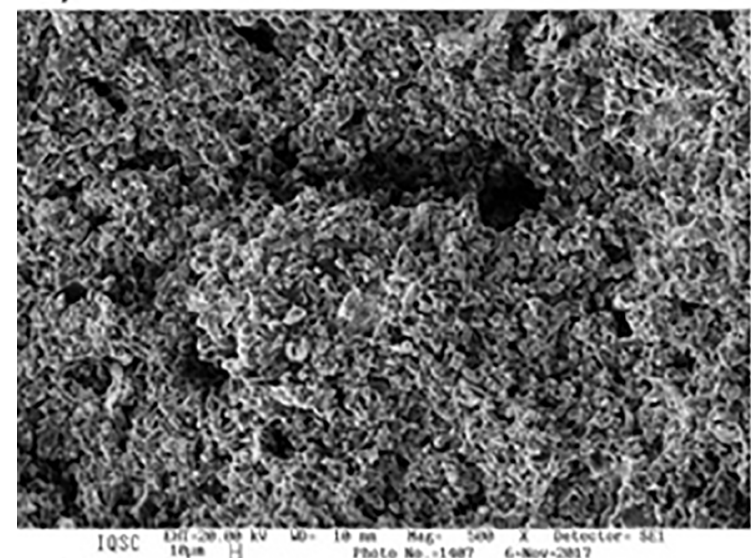

c) format. Then the induction period starts with the formation of new crystals that envelop the first crystals formed. After that, the final stage of hydration begins, the reaction speed decreases, because there is little concentration of ions $\mathrm{Ca}^{2+}$ and $\mathrm{SO}_{4}^{2-}$; however, crystal formation still occurs and they will be those who offer a major or minor structural robustness to the gypsum, since the formation of these last crystals replaces the spaces filled by water molecules, if these crystals do not form, the unused water will evaporate over time and the empty space will cause an increase in the porosity of the material, weakening it ${ }^{9}$. For the authors, the hydration of anhydrite II during the last stage of hydration grants its resistance by filling in the remaining pores.

In the reference sample (Figure 3 (a)) there is an intense and compact formation of gypsum crystals with a few voids left by the water molecules that have not responded during the hydration process. Figure 3 (b) shows the modified gypsum with $10 \%$ EVA, there is less presence of crystals and a greater distribution of voids. The polymer film is barely visible, and its constitution was not continuous but similar to filaments. In the modified matrix with $10 \% \mathrm{VA} / \mathrm{VL} / \mathrm{VC}$ (Figure 3 (c)),

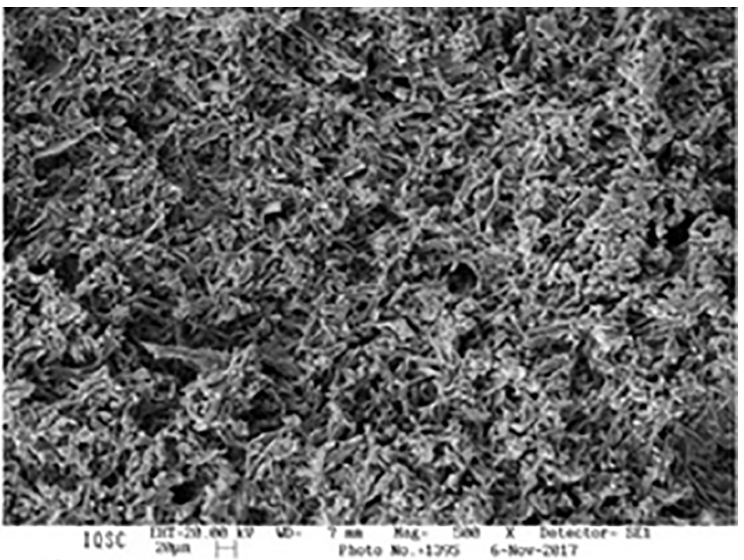

b)

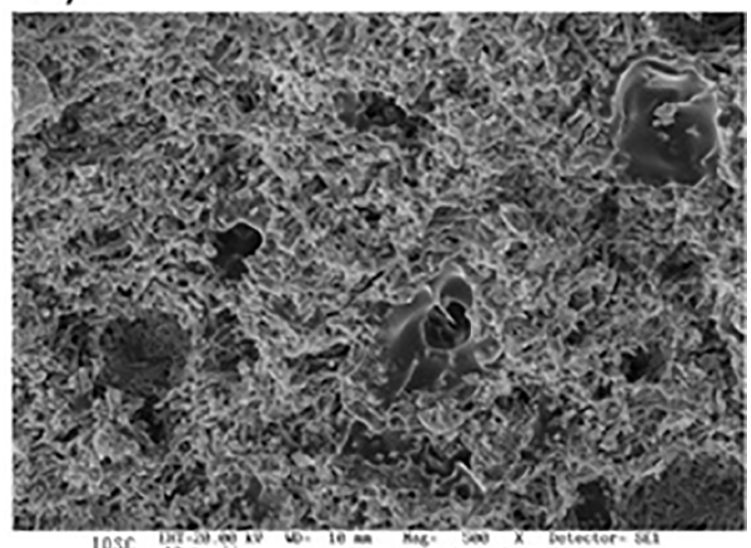

d)

Figure 3. Matrix - 500X Magnification: (a) without polymer. Modified matrix with 10\%: (b) EVA; (c) VA/VL/VC; (d) VA/VeoVA. 
we verified that the polymeric material enveloped a few sets of crystals, but without making a connection between these groups, giving a flocculated aspect. Probably the absence of polymeric film caused a minor grip between crystals, as it was the lowest result of bending strength. The addition of $10 \% \mathrm{VA} / \mathrm{VeoVA}$ (Figure $3(\mathrm{~d})$ ) provided a clearer presence of polymer film, however it was not continuous, with concentrated regions of film along with large voids. The gypsum crystals are not enveloped completely, leaving spaces between the blocky crystals. This may have compromised the desired increase in the mechanical performance, but the mixture obtained was still the highest value in the result of flexural strength. The excess water also hinders or may prevent the crystals from bonding. Thus, the water/gypsum ratio may have contributed to reducing the formation of crystals, because it increased porosity due to the excess water present in the matrix. In addition, this level may also have led to the formation of crystals with smaller expansion, hindering the bond between crystals to form larger sets and thus provide greater compactness ${ }^{20}$.

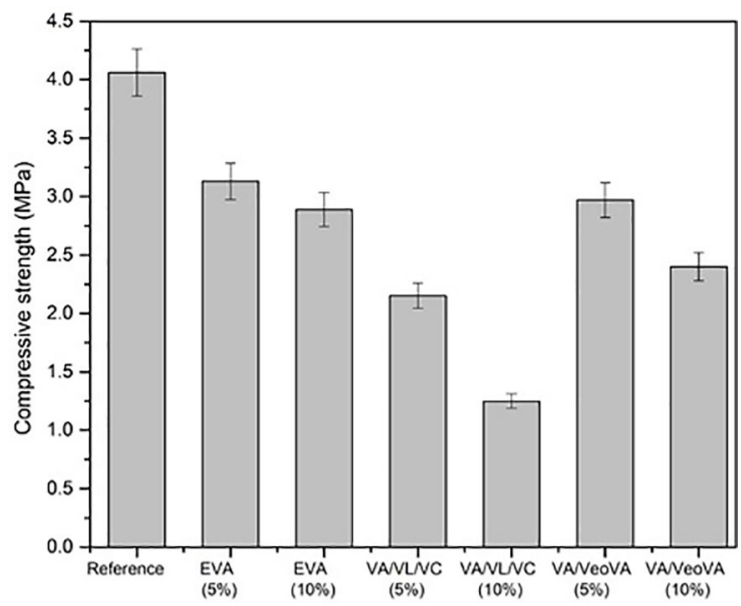

Figure 4. Compressive strength of modified gypsum.

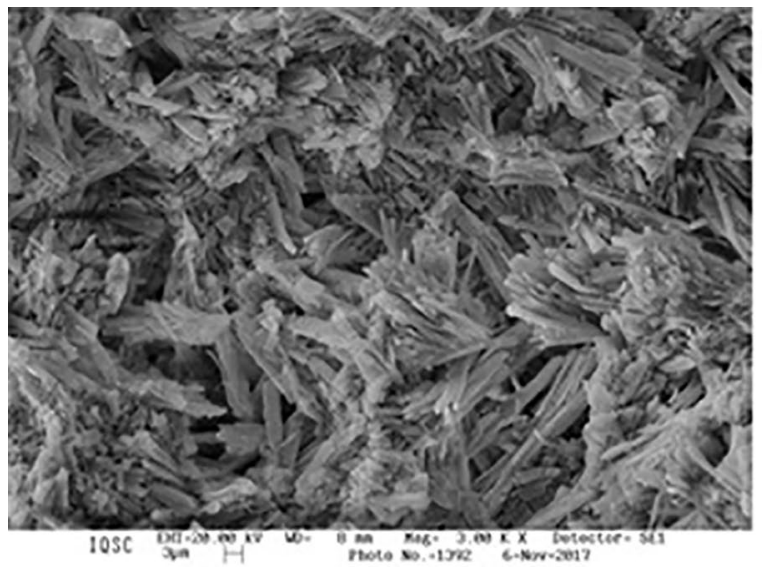

Counts

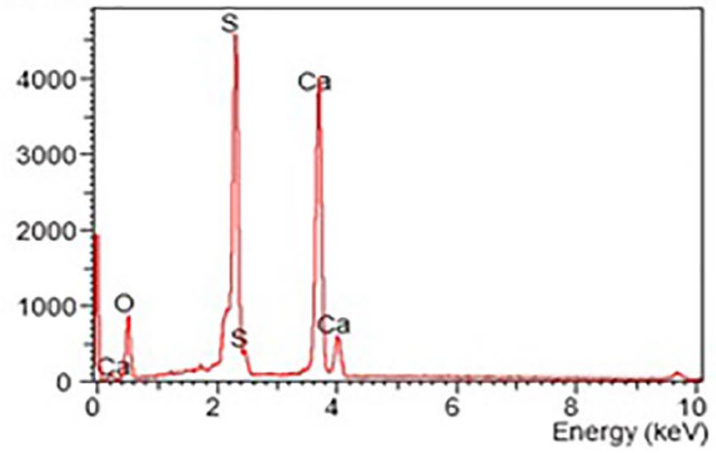

The reference sample resulted in the compressive strength of 3.91 MPa, above the modified gypsum (Figure 4). In this sample we can verify the crystal arrangements formed by sets of acicular crystals in different orientations (Figure 5). The best results for the modified matrices were observed for samples with addition of EVA, especially at a rate of $5 \%$.

Figure 6 and 7 show the SEM images of modified gypsum with $5 \%$ and $10 \%$ of the polymer, respectively. The EVA did not alter the formation of gypsum crystals coalescing more dispersedly, contrary to VA/VeoVA, which coalesced in a more concentrated way in several regions. The gypsum composite with addition of $10 \%$ of VA/VL/VC showed greater decrease in compression strength compared with the reference, repeating the same behavior observed for the flexural strength. In fact, the VA/VL/VC terpolymer changed substantially the microstructure of the gypsum. The acicular crystals formed are less brittle-looking. Among the three polymers analyzed, the VA/VL/VC was the one that damaged the structural robustness of the composite, hindering the formation of longer gypsum crystals without greater microstructural overlapping.

EDS analysis show the influence of polymers on the gypsum plaster microstructure. The polymers decreased the levels of $\mathrm{Ca}$ and $\mathrm{S}$, evidently because of the greater concentration of $\mathrm{C}$ and $\mathrm{O}$. For the VA/VL/VC terpolymer there was the appearance of $\mathrm{Cl}$ originated from vinyl chloride. The approximated concentration of elements is provided in Table 2. The EDS images corroborate the results presented in the SEM images and mechanical results where the gypsum with addition of $10 \%$ EVA presented a greater quantitative of $\mathrm{Ca}$ and $\mathrm{S}$, which constitute the elements of the crystals of calcium sulfate dihydrate $\left(\mathrm{CaSO}_{4} \cdot 2 \mathrm{H}_{2} \mathrm{O}\right)$, followed by the sample with the addition of $10 \%$ of VA/VeoVA and $10 \%$ addition of VA/VL/VC with the smallest amount of $\mathrm{Ca}$ and $\mathrm{S}$ and lower axial compression results.

Figure 5. SEM and EDS of the reference sample. 


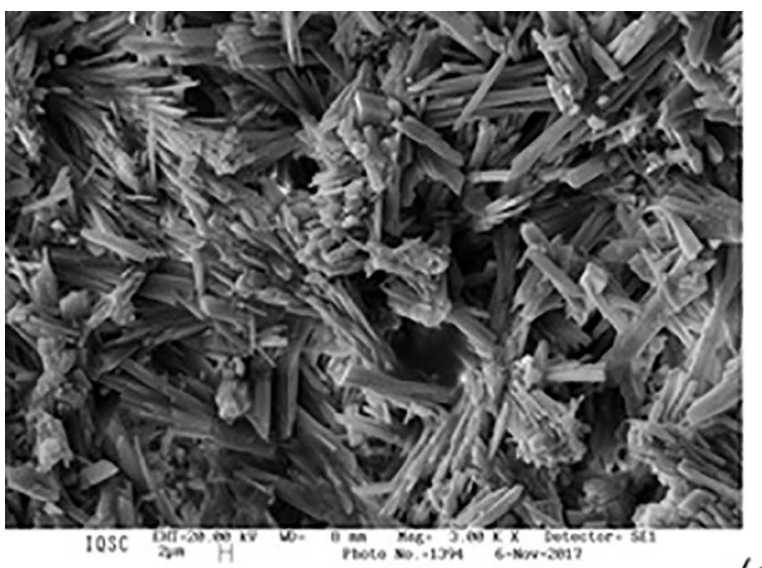

Counts

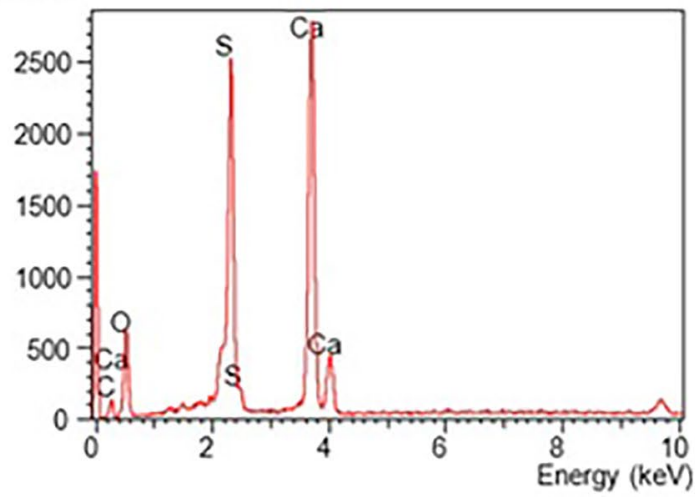

(a)

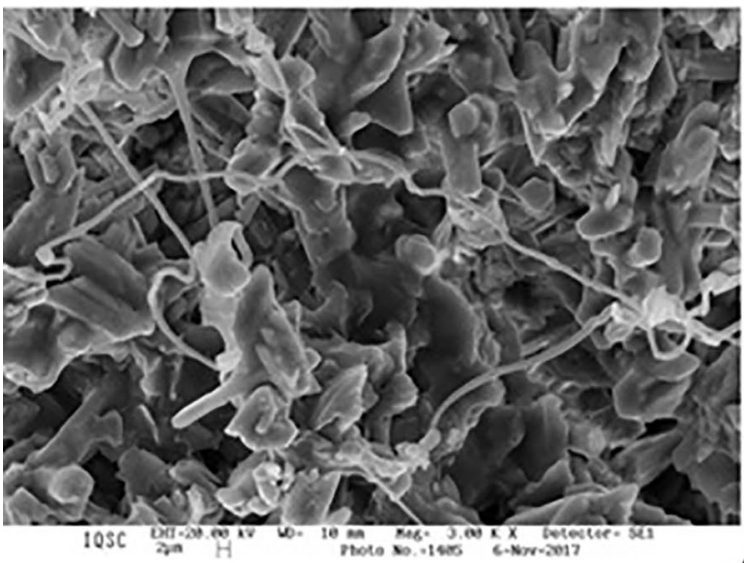

\section{Counts}

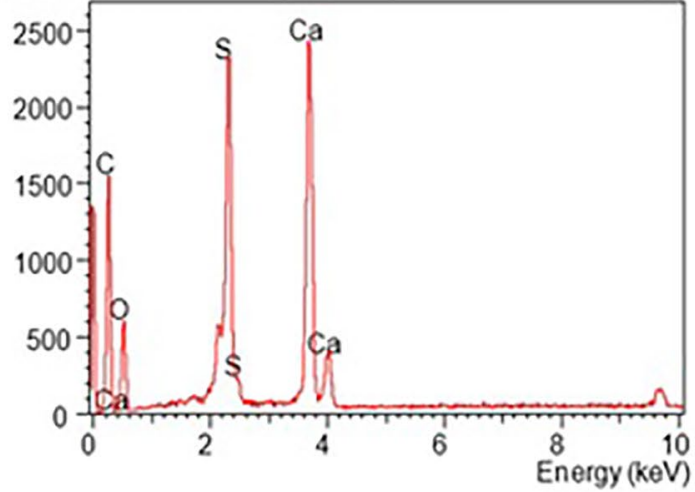

(b)

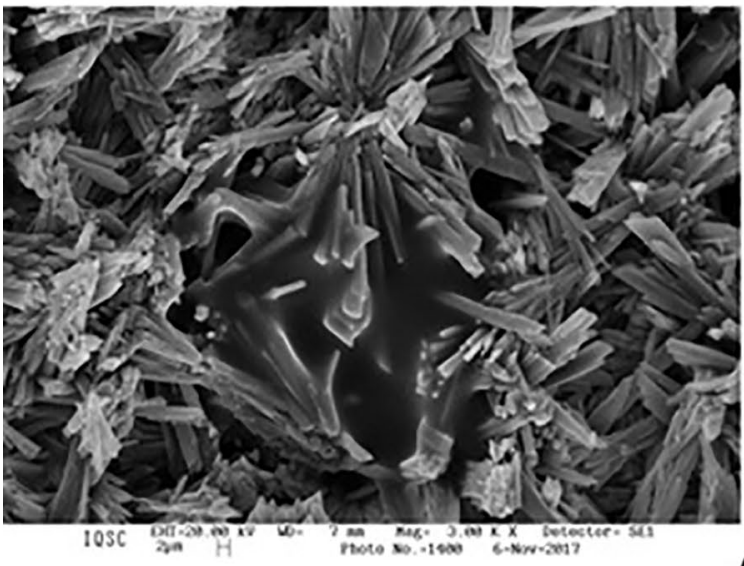

Counts

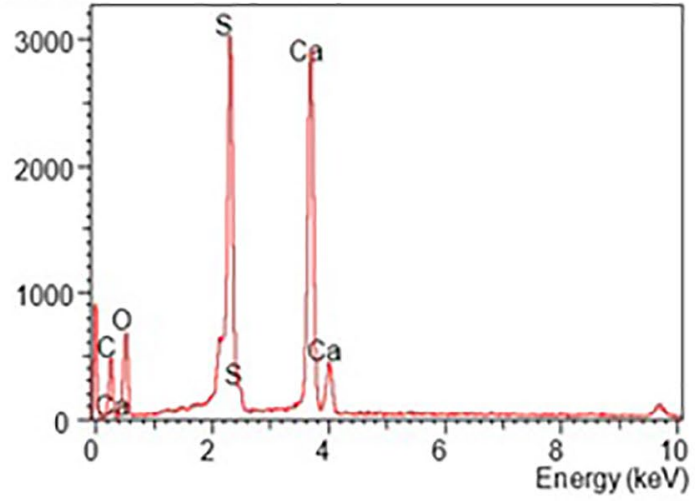

(c)

Figure 6. SEM and EDS of the sample with addition of 5\% polymer: (a) EVA; (b) VA/VL/VC; (c) VA/VeoVA. 

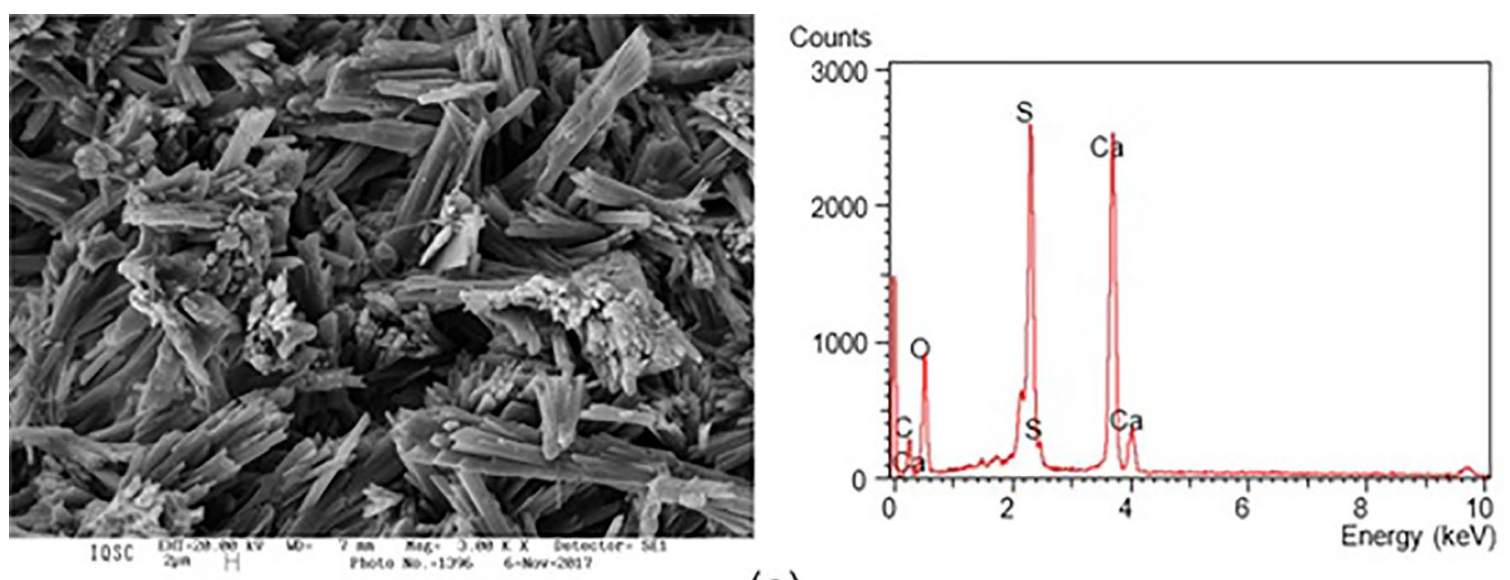

(a)
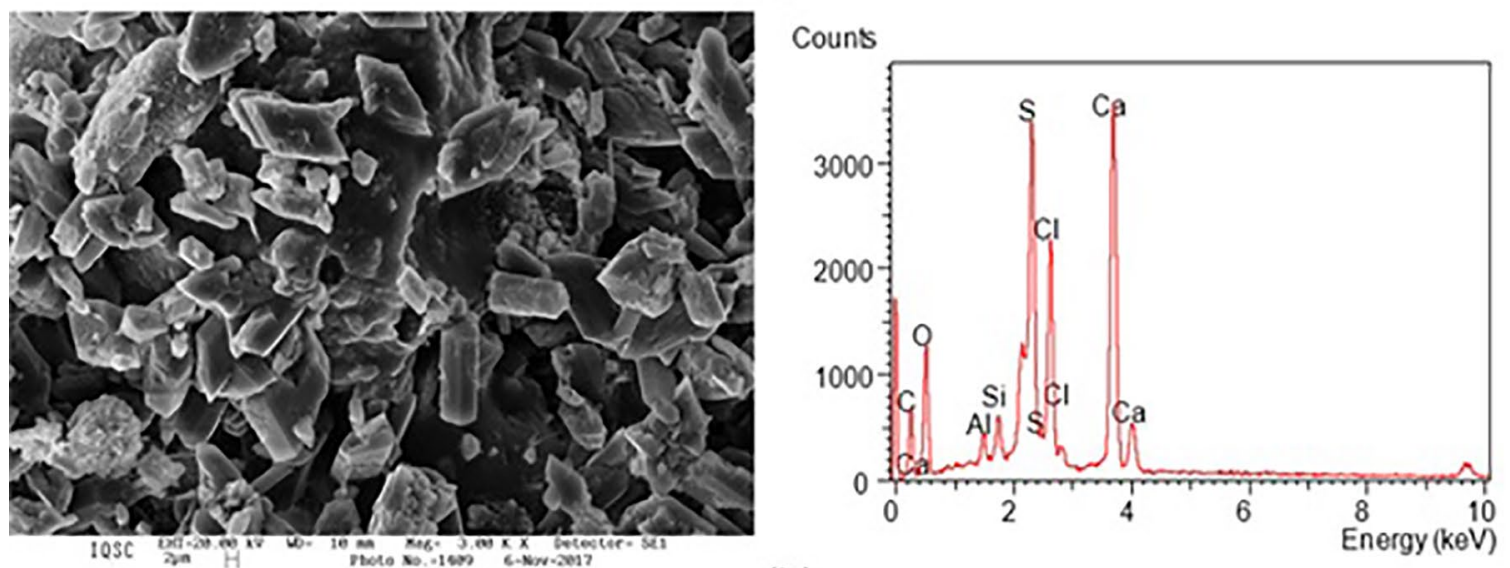

(b)
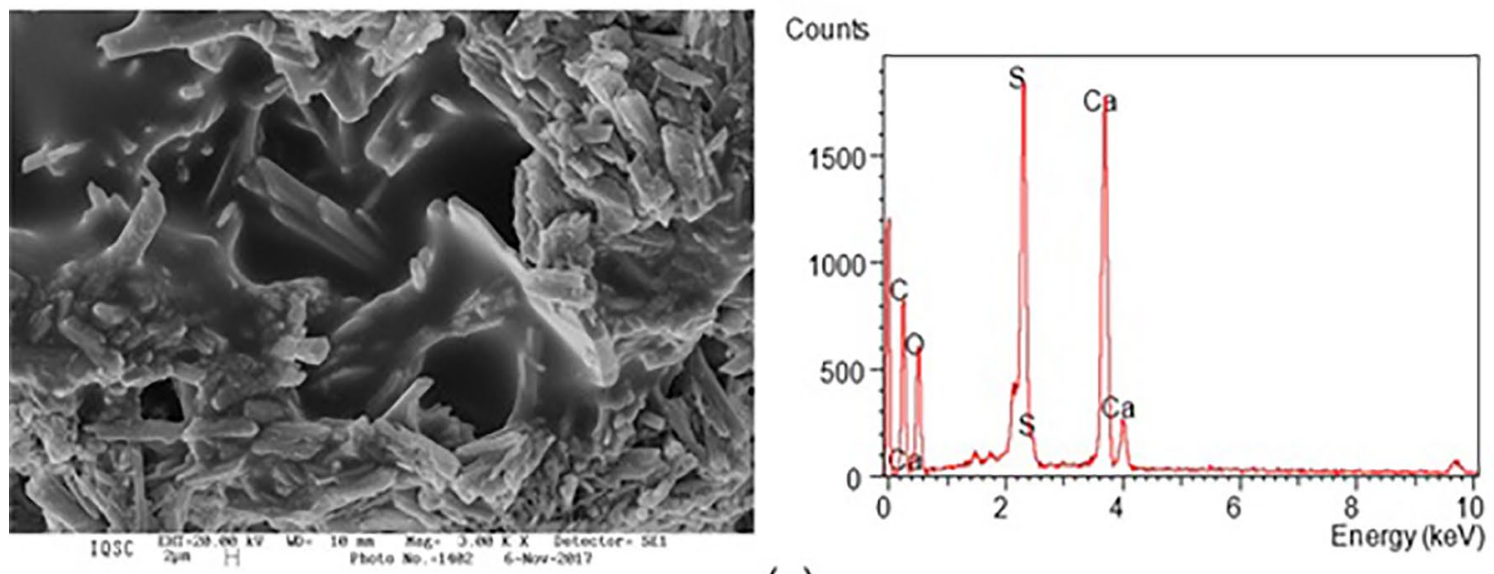

(c)

Figure 7. SEM and EDS of the sample with addition of 5\% polymer: (a) EVA; (b) VA/VL/VC; (c) VA/VeoVA. 
Table 2. Chemical composition of samples obtained by EDS.

\begin{tabular}{|c|c|c|c|c|c|c|}
\hline Sample & $\begin{array}{c}\text { Polymer } \\
\text { content }(\%)\end{array}$ & O (\%) & $\mathrm{C}(\%)$ & S (\%) & Ca $(\%)$ & Cl (\%) \\
\hline Referência & 0 & 45.66 & - & 20.76 & 33.58 & - \\
\hline \multirow{2}{*}{ EVA } & 5 & 43.06 & 10.76 & 15.07 & 23.33 & -- \\
\hline & 10 & 46.29 & 17.08 & 13.30 & 23.33 & \\
\hline \multirow{2}{*}{$\mathrm{VA} / \mathrm{VL} / \mathrm{VC}$} & 5 & 30.56 & 43.05 & 8.76 & 17.63 & - \\
\hline & 10 & 40.14 & 25.03 & 7.88 & 18.76 & 8.20 \\
\hline \multirow{2}{*}{ VA/VeoVA } & 5 & 37.96 & 24.05 & 13.60 & 24.38 & - \\
\hline & 10 & 37.65 & 36.38 & 9.46 & 16.51 & - \\
\hline
\end{tabular}

\section{Conclusions}

The simple addition of polymers EVA, VA/VeoVA and VA/VL/VC did not show better performance and structural robustness to the gypsum matrix. We observed that there is a more intense reduction for larger levels of polymers. Among the three polymers analyzed EVA showed the best performance. The main conclusions of this study were:

I. The VA/VL/VC terpolymer has higher potential of hydration inhibition of the gypsum, even altering its microstructural formation.

II. The decrease in flexural strength under bending or compression can be justified by the microstructural analysis that showed a smaller compactness for the modified matrices compared with the reference matrix. This fact can be attributed to the incorporation of air, characteristic inherent in the technology.

III. Even with the reduction of the values of compression strength, the gypsum with 10\% EVA obtained values that can be used to produce sealing blocks with no structural purposes.

IV. The formation of film became more evident in the composites modified by VA/VeoVA. However, the formation of fibrils was already evidenced in the samples modified by VA/VL/VC.

Probably, to achieve better mechanical properties is necessary the employment of additives that can improve their compactness and minimize the incorporation of air. This need becomes more intense as the ability to incorporate air in the polymer and changes in the plasticity of the gypsum plaster increases. We also concluded that the reduction in the amount of water through additives may allow a more complete and robust formation of gypsum crystals and compounds with better mechanical performance.

\section{Acknowledgments}

The authors would like to express their gratitude to the Wacker Quimica do Brasil Ltda. and Espaço da Escrita/ UNICAMP - for the language services provided. The authors M. E. Araújo and S. Beloti acknowledge Coordination for the Improvement of Higher Education Personnel (CAPES) for the financial support. The author S. Beloti would like to thank to Federal Institute of South of Minas Gerais, Campus Poços de Caldas.

\section{References}

1. Çolak A. Characteristics of acrylic latex-modified and partially epoxy-impregnated gypsum. Cement and Concrete Research. 2001;31(11):1539-1547.

2. Rubio-Avalos JC, Manzano-Ramírez A, Luna-Bárcenas JG, Pérez-Robles JF, Alonso-Guzmán EM, Contreras-García ME, et al. Flexural behavior and microstructure analysis of a gypsum-SBR composite material. Materials Letters. 2005;59(2-3):230.

3. Çolak A. Physical and mechanical properties of polymer-plaster composites. Materials Letters. 2006;60(16):1977-1982.

4. Wu H, Xia Y, Hu X, Liu X. Improvement on mechanical strength and water absorption of gypsum modeling material with synthetic polymers. Ceramics International. 2014;40(9 Pt B):14899-14906.

5. Mróz P, Mucha M. Hydroxyethyl methyl cellulose as a modifier of gypsum properties. Journal of Thermal Analysis and Calorimetry. 2018;134(2):1083-1089.

6. Richerson DW. Modern Ceramic Engineering: Properties, Processing, and Use in Design. 2nd ed. Boca Raton: CRC Press; 1992.

7. Launey ME, Ritchie RO. On the Fracture Toughness of Advanced Materials. Advanced Materials. 2009;21(20):2103-2110.

8. Ohama Y. Handbook of Polymer-Modified Concret Mortars. New York: Elsevier; 1995. p. 157-174.

9. Tazawa E. Effect of Self Stress on Flexural Strength of GypsumPolymer Composites. Advanced Cement Based Materials. 1998;7(1):1-7.

10. Zhu C, Zhang J, Peng J, Cao W, Liu J. Physical and mechanical properties of gypsum-based composites reinforced with PVA and PP fibers. Construction and Building Materials. 2018;163:695-705.

11. Khalil AA, Tawfik A, Hegazy AA, El-Shahat MF. Effect of some waste additives on the physical and mechanical properties of gypsum plaster composites. Construction and Building Materials. 2014;68:580-586.

12. Wu Q, Zhu Z, Li S, Wang S, Chen B. Effect of polyacrylic ester emulsion on mechanical properties of macro-defect free desulphurization gypsum plaster. Construction and Building Materials. 2017;153:656-662. 
13. ASTM International. ASTM C472-99 - Standard Test Methods for Physical Testing of Gypsum, Gypsum Plasters and Gypsum Concrete. West Conshohocken: ASTM International; 2014.

14. ASTM International. ASTM C348-14 - Test Method for Flexural Strength of Hydraulic-Cement Mortars. West Conshohocken: ASTM International; 2014.

15. ASTM International. ASTM C349-14 - Standard Test Method for Compressive Strength of Hydraulic-Cement Mortars (Using Portions of Prisms Broken in Flexure). West Conshohocken: ASTM International; 2014.

16. Gmouh A, Eve S, Samdi A, Moussa R, Hamel J, Gomina M. Changes in plaster microstructure by pre-stressing or by adding gypsum grains: microstructural and mechanical investigations. Materials Science and Engineering: A. 2003;352(1-2):325-332.
17. Karni J, Karni E. Gypsum in construction: origin and properties. Materials and Structures. 1995;28(2):92-100.

18. Magallanes-Rivera RX, Escalante-García JI, Gorokhovsky A. Hydration reactions and microstructural characteristics of hemihydrate with citric and malic acid. Construction and Building Materials. 2009;23(3):1298-1305.

19. Eve S, Gomina M, Hamel J, Orange G. Investigation of the setting of polyamide fibre/latex-filled plaster composites. Journal of the European Ceramic Society. 2006;26(13):2541-2541.

20. Lewry AJ, Williamson J. The setting of gypsum plaster: Part II The development of microstructure and strength. Journal of Materials Science. 1994;29(21):5524-5528. 